\title{
O POSICIONAMENTO DISCURSIVO A PROPÓSITO DE AÇÕES SOCIOAMBIENTAIS ENUNCIADAS POR EMPRESAS EM REVISTA
}

\author{
Rosângela Rocio Jarros Rodrigues \\ Universidade Estadual de Londrina - UEL - Curso de Psicologia, Departamento de Psicologia Social e Institucional, \\ Londrina, PR. E-mail: jarros@uel.br
}

\begin{abstract}
RESUMO
O posicionamento discursivo a propósito das ações ambientais trata de posições declaradas pelo enunciador das organizações quanto ao cuidado com o meio ambiente. Os posicionamentos discursivos podem ser três: de neutralidade, de engajamento e de distanciamento. Todo dizer é orientado pelas formações discursiva e ideológica. O método desta pesquisa é qualitativa, documental e orienta-se pelos pressupostos da Análise de Discurso de linha francesa. O corpus analisado é composto por quinze exemplares de uma revista nacional. Os resultados indicam seis focos de ações socioambientais. Identificamos os posicionamentos discursivos na fala do enunciador: distanciamento e engajamento. O primeiro é marcado pela ausência de declarações de ações socioambientais e o segundo é de engajamento-conciliador. Todavia, a relação polêmica está entre o discurso de engajamento-conciliador o engajamento-responsável da organização por problemas ambientais. Conclui-se que as ações socioambientais tem como foco o comportamento de trabalhadores e comunidade externa à organização.

Palavras-chave: Meio ambiente, Ações socioambientais, Análise de discurso, Posicionamento discursivo, Organizações.

\section{THE DISCURSIVE POSITIONING WITH REGARD TO SOCIAL AND ENVIRONMENTAL INITIATIVES SET OUT BY COMPANIES IN THE MAGAZINE}

\begin{abstract}
The discursive positioning regarding environmental initiatives about positions declared by enunciator of the organizations regarding the care for the environment. The discursive placements can be three: of neutrality, of engagement and detachment. All say is driven by an ideological and discursive formations. The method of this research is qualitative, and documentary directed by the assumptions of the analysis of discourse of French line. The parsed corpus is composed of fifteen copies of a national magazine. The results indicate six foci of environmental actions. Identify the discursive placements on talks about the enunciator: detachment and engagement. The first is marked by the absence of claims of environmental actions and the second is to engage-conciliator. However, the controversy is between the speech of engagement-conciliatory engagement-the organization responsible for environmental problems. It is concluded that the environmental actions have focused on the behavior of employees and external community to the organization. Keywords: Environment, Environmental actions, Analysis of discourse, Discursive positioning, Organizations.
\end{abstract}




\section{INTRODUÇÃO}

A temática sobre o meio ambiente tem despertado interesse de várias áreas de conhecimento e de diferentes atores sociais. Configura-se como área de estudo interdisciplinar e, nesse sentido, a psicologia traz contribuições valiosíssimas, pois pretende provocar mudanças no comportamento humano que levem a atitudes pró-ambientais agindo por meio de estratégias de sensibilização das pessoas. $\mathrm{Na}$ área da Psicologia contamos com o tributo da Psicologia Ambiental inicialmente mais centrada em estudos da linha "arquitetônica" e que se amplia ao se preocupar com a ação das pessoas sobre o meio ambiente inaugurando assim a Psicologia Ambiental "verde" (MOSER, 2005; 1998). Nesse movimento, a obra de Cavalcante e Elali (2011) enriquece e ilustra as duas linhas de estudos da psicologia ambiental e quanto à linha "verde" apresentam capítulos específicos, como o comportamento ecológico, compromisso pró-ecológico, valores ecológicos, desenvolvimento sustentável, gestão ambiental entre outros. Leitura importante para os psicólogos que atuam cotidianamente em empresas.

Os psicólogos que trabalham em empresas, tradicionalmente com a atuação voltada para a gestão de pessoas, tem se defrontado com a demanda de participar das ações referentes à gestão ambiental. A gestão ambiental, segundo Rodrigues (2015b, p. 180) é uma

ferramenta que as organizações utilizam para comunicar ações planejadas para anular ou reduzir o impacto nocivo dos resíduos e ou produtos frente ao meio ambiente empreendendo esforços para educar trabalhadores, comunidade, fornecedores e clientes acerca da adoção de comportamentos ecológicos fundamentados nos princípios do desenvolvimento sustentável.

As organizações estão sendo obrigadas a adotarem políticas e práticas de cuidado e preservação do meio ambiente por força de legislação nacional e internacional, bem como as exigências dos consumidores mais conscientizados. Sabe-se que "todo projeto industrial, desenvolvimento urbano ou oferta de serviço implica em modificações em seu entorno, um impacto ambiental que pode afetar mais do que o local físico", ressalta Pol (2003, p. 235).

Macêdo et al. (2013) indicam os desafios da gestão ambiental para os psicólogos e destacam como prioritário o envolvimento da alta direção (os empresários) constituindo a primeira etapa do trabalho nas organizações. De modo muito claro detalham como o psicólogo pode atuar e recomendam, principalmente, a via do treinamento de pessoal. Entretanto, nossa investigação não vai à direção do fazer do psicólogo em gestão ambiental, porém, investiga o posicionamento discursivo do porta-voz da empresa conforme os pressupostos da Análise de Discurso de Michel Pêcheux.

Sobre a diversidade de atores sociais envolvidos diretamente com a temática do meio ambiente, há a comunidade discursiva empresarial no tocante à gestão ambiental como vimos anteriormente. No espaço discursivo das organizações encontramos a temática do meio ambiente sendo abordada e tomando parte em seu discurso. Essas buscam, por sua vez, divulgar a competência das suas organizações e utilizam gêneros textuais específicos como revistas nacionais que possibilitem atingir esse objetivo.

Nota-se que todo texto é constituído por uma "trama enunciativa" (RODRIGUES, 2015c). Essa trama é tecida a partir de vários discursos que o constitui, pois acreditamos que um enunciado não surge do nada. Ele compõe uma unidade do ato de enunciação que está ligado a uma determinada formação discursiva (doravante denominada de FD) e o enunciador revela sua 'competência discursiva' ao reproduzir o que pode e deve ser dito, ou seja, usa os enunciados próprios da FD, destaca Maingueneau (2005a).

O discurso se constitui em seus sentidos porque aquilo que o sujeito diz se inscreve em uma formação discursiva e não outra para ter um sentido e 
não outro. [...] as palavras não têm um sentido nelas mesma, elas derivam seus sentidos de formações discursivas em que se inscrevem. As formações discursivas, por sua vez, representam no discurso as formações ideológicas. Desse modo, os sentidos sempre são determinados ideologicamente. Não há sentido que não o seja. Tudo que dizemos tem, pois, um traço ideológico em relação a outros traços ideológicos. [...] no discurso, a ideologia produz seus efeitos, materializando-se nele. (ORLANDI, 2005, p.43)

A FD, por sua vez, "se define como que uma formação ideológica - ou seja, a partir de uma posição dada em uma conjuntura sócio-histórica dada - determina o que pode e de ser dito", conforme Orlandi (2005, p. 43). Para a Análise de Discurso (doravante denominada de AD) a formação ideológica é constitutiva do pensar, que orienta e determina o dizer, o que pode e deve ser dito, ou seja, a FD.

Determinada comunidade partilha de um campo discursivo definível como um conjunto de FDs (ou posicionamentos) que se encontra em relação de concorrência, ou seja, inserida num jogo de equilíbrio instável, em que cada FD delimita-se por uma posição enunciativa com as outras (MAINGUENEAU, 1997). Contudo, a AD não se propõe a estudar um campo discursivo em sua totalidade, segundo o autor, mas sim extrair um subconjunto correspondente ao espaço discursivo, constituído de ao menos dois posicionamentos discursivos, cuja correlação é considerada importante pelo analista.

Quando, no espaço discursivo, se estabelecem pelo menos dois posicionamentos é possível que aí esteja evidenciada a relação polêmica, no sentido de um discurso sempre ser estabelecido em relação com o Outro, o que para Maingueneau (2005a) torna possível a identidade de cada discurso. Hoje na $A D$ também se emprega o termo posicionamento para caracterizar a FD do enunciador. $O$ posicionamento é uma das categorias basilares da $A D$, que trata da instauração e da conservação da identidade enunciativa (RODRIGUES, 2011). Para Charadeau e Maingueneau (2004, p. 267), a identidade de posicionamento caracteriza "a posição que o sujeito ocupa em um campo discursivo em relação aos sistemas de valor que aí circulam, não de forma absoluta, mas em função dos discursos que ele mesmo produz".

Um campo de atividade social é constituído por comunidades discursivas que têm campo e espaço discursivos específicos. Segundo Charaudeau e Maingueneau (2004, p. 108), "os modos de organização dos homens e de seus discursos são indissociáveis das instituições que as fazem emergirem e que as mantêm". As comunidades discursivas podem ser agrupadas por estarem baseadas na economia; na produção de valores e crenças ideológicas; pela circulação de textos em diferentes veículos midiáticos e pela natureza das atividades técnicas e científicas.

O sujeito discursivo, como membro de determinada comunidade, é interpelado a se posicionar. Existem três tipos de posicionamentos, que correspondem aos de:

(1) colocar-se em uma posição enunciativa de neutralidade quanto à opinião que exprime, "posição que o levará a apagar, em seu modo de argumentação, qualquer traço de julgamento e de avaliação pessoal, seja para explicitar as causa de um fato, seja para demonstrar uma tese"; (2) colocar-se em uma posição de engajamento, "o que conduzirá o sujeito, contrariamente ao caso precedente, a optar (de maneira mais ou menos consciente) por uma tomada de posição na escolha dos argumentos ou na escolha das palavras, ou por uma modalização avaliativa associada a seu discurso", o que produzirá um discurso de convicção destinado a ser partilhado pelo interlocutor; (3) colocar-se numa posição de distanciamento que o levará a tomar a atitude fria do especialista que 
analisa sem paixão, como faria um expert. (CHARAUDEAU; MAINGUENEAU, 2004, p. 143)

A interpelação se dá pela identificação do sujeito com a FD que o domina e, nesse caso, o tipo de posicionamento mais esperado é de engajamento. Os posicionamentos de neutralidade e distanciamento abrem um espaço para a diferença, para a contradição, que indicará divergências de posições do sujeito no interior de uma mesma FD.

O objetivo central desse estudo é apresentar os discursos que tecem a trama enunciativa com relação a ações socioambientais empreendidas, dentro e fora do espaço do trabalho, por organizações empresariais no tocante a temática meio ambiente.

\section{MÉTODO}

Este trabalho é um recorte da pesquisa intitulada "Estética organizacional e saúde no trabalho: os discursos transversos da trama enunciativa", desenvolvida na Universidade Estadual de Londrina, na área de psicologia organizacional e do trabalho. Esta é uma pesquisa qualitativa e nesta os dados " se dão em um contexto fluente de relações, são "fenômenos" que não se restringem às percepções sensíveis e aparentes, mas se manifestam em uma complexidade de oposições, de revelações e de ocultamentos. É preciso ultrapassar sua aparência imediata para descobrir sua essência" (CHIZZOTTI, 2003, p.84).

A fonte empregada é documental (RICHARDSON, 2008), desse modo o corpus é constituído por quinze exemplares publicados no período de 2000 a 2015, pela Revista Exame da Editora Abril, especificamente a edição especial de "Você S/A", intitulada as "melhores empresas para se trabalhar". Os exemplares são publicados anualmente e a seção em análise é das "10 melhores empresas". A técnica de interpretação do corpus segue os pressupostos da análise de discurso de linha francesa (PÊCHEUX, 1997).

\section{RESULTADOS}

Os resultados indicam que na Revista "As Melhores Empresas para se Trabalhar" no Brasil, alguns exemplares há o silêncio sobre declarações de ações socioambientais desenvolvidas por aquelas que constam na seção "As dez melhores Empresas". O silêncio é a ausência nos textos analisados de conteúdo que mencione alguma ação socioambiental.

Em contrapartida, identificamos que em outros exemplares há publicação de ações socioambientais. Conforme Rodrigues (2015a) seis focos de ações são constatadas no período citado anteriormente, a saber: 1) incentivo à coleta seletiva e a reciclagem de materiais (elaboração de estratégias de descontos e pagamentos), 2) a comercialização de resíduos recicláveis visando o retorno do dinheiro a funcionários (bolsas de estudos) e a comunidade externa (cestas básicas), 3) a definição e divulgação de políticas que favoreçam o cuidado e a preservação do meio ambiente (Carta Ambiental, Canal aberto de Comunicação), 4) o uso de material reciclado nas atividades diárias da empresa (reuso de papel), 5) os investimentos para redução do consumo de energia elétrica (troca de lâmpadas) e tratamento da água (efluentes) utilizada no processo de produção, e 6) abastecimento dos veículos com (etanol, descarte de baterias) entre outras ações.

\section{DISCUSSÃO}

Dois posicionamentos discursivos estão evidenciados no corpus analisado, a saber, o de neutralidade em virtude do silêncio e o de engajamento a partir da identificação dos seis focos de ações socioambientais. Estes dois posicionamentos não chegam a estabelecer entre si uma relação polêmica, todavia, constituem os discursos do enunciador em tempos diferentes. 
O silêncio representa um posicionamento discursivo, assim em certas condições sociais e históricas de produção não é objetivo do enunciador compor a imagem da sua organização a partir do discurso de engajamento. De algum modo o silêncio pronuncia o atendimento do interesse daquela comunidade discursiva.

Retomando o posicionamento discursivo de engajamento, logo, o desenvolvimento de ações socioambientais, isso provoca certo estranhamento no analista do discurso, pois o enunciador é o representante, o porta-voz legal do campo discursivo da economia, desse modo, do lucro e, obrigatoriamente, se insere num campo conflituoso. Conflituoso porque de um lado tem a demanda da produção, talvez gerando danos ambientais, mas projeta a imagem de cuidador do meio ambiente. Parece que temos uma FI de engajamento- conciliação.

A FI engajamento-conciliação contrasta com o lugar social e ideológico que ocupa no campo discursivo da economia. Desse modo, seria possível a um provável explorador de recursos naturais, ao mesmo tempo, ser um cuidador do meio ambiente? Parece que o enunciador quer fazer crer que é sim engajado em defesa do meio ambiente, porém, o discurso avesso é a FI do engajado, mas, em parte, quando não se responsabiliza como um possível agente de prejuízos ao mesmo meio ambiente. $O$ enunciador se distancia do engajamento responsável. Vê-se, então, estabelecida a tensão, a relação polêmica entre duas formações ideológicas, uma FI de engajamento-conciliador em oposição a FI de engajamento-responsabilizador.

A relação polêmica se evidencia quando constatamos que discursivamente, a partir dos seis focos de ações socioambientais, voltadas para a "educação" ambiental se polemiza o discurso avesso, ou seja, o enunciador não trata nesses focos como, por exemplo, a empresa tratando do seu processo de trabalho, do seu uso de matérias-primas que muitas vezes advém dos recursos naturais finitos extraídos da natureza, da poluição que lança no ar, na água e no solo, ou comprometendo-se em rever sua ação e minimizar os danos causados ao meio ambiente (DIAS, 2006; TACHIZAWA, 2007; CÂMARA, 2009; MACÊDO et al., 2013).

Os focos de ações socioambientais ficam circunscritos, como ressalta Rodrigues (2015b), à educação ambiental do trabalhador e da comunidade entorno da empresa, como a destinação correta do lixo, sobre a mudança de procedimentos que visem à economia e redução de custos e outros, no entanto, permanece velado a propósito como está o processo de produção dos produtos fabricados pela organização em questão.

O conflito não é tratado abertamente nesse campo discursivo, ora o enunciador se mantém neutro e não declara ações socioambientais ou quando se posiciona projeta a imagem de enunciador engajado-conciliador, contudo, não há engajamento-responsável, pois o faz de forma periférica, na realidade o enunciador adota o posicionamento de distanciamento já que não se coloca como um dos pivôs dos danos ambientais.

Os valores socioambientais que circulam nesse campo discursivo implicaria o enunciador à posição de engajamento-responsabilizador, o que levaria a publicar práticas e políticas comprometidas com a mudança do processo de produção em vistas ao cuidado com o meio ambiente.

\section{CONCLUSÃO}

Conclui-se que essas ações socioambientais citadas demonstram que valores sustentáveis estão sendo incorporados ao cotidiano das pessoas e que comportamentos pró-ambientais são estimulados pelas organizações e até na comunidade do entorno das empresas. Todavia, ainda parece ser um discurso de engajamento-conciliador que apaga o discurso avesso, o posicionamento do engajamento-responsável. Sendo assim, verifica-se uma tendência à adoção de ações socioambientais voltadas para o cuidado e a preservação com o meio ambiente, porém periférico, tímido. O psicólogo nas organizações poderá contribuir efetivamente por meio de treinamentos junto aos gestores das empresas em primeiro lugar e aos demais trabalhadores, 
fornecedores, clientes e comunidade. Reputamos como imprescindível ao psicólogo desvelar para si e para os demais o processo de subjetivação implicada nos atos de consumir e descartar (RODRIGUES; MANSANO, 2013) que todos nós estamos envolvidos.

\section{REFERÊNCIAS}

CÂMARA, R. P. de B. Desenvolvimento sustentável. In: ALBUQUERQUE, J. L. (Org.). Gestão ambiental e responsabilidade social: conceitos, ferramentas e aplicações. São Paulo: Atlas, 2009. p. $70-92$

CAVALCANTE, S.; ELALI, G. A. Temas básicos em psicologia ambiental. (Org.). Petrópolis, RJ: Vozes, 2011.

CHARAUDEAU, P.; MAINGUENEAU, D. Dicionário de Análise do Discurso. São Paulo: Contexto, 2004.

CHIZZOTTI, A. Pesquisa em ciências humanas e sociais. 6. ed. São Paulo: Cortez, 2003.

DIAS, R. Gestão ambiental: responsabilidade social e sustentabilidade. São Paulo: Atlas, 2006.

MAINGUENEAU, D. Gênese dos discursos. Curitiba, PR: Criar, 2005a.

. Ethos, cenografia, incorporação. In: AMOSSY, R. (Org.). Imagens de si no discurso: a construção do ethos. São Paulo: Contexto, 2005b. p. 29-87.

. Novas tendências em análise do discurso. 3. ed. Campinas, SP: UNICAMP, 1997.

MACÊDO, K. B.; OLIVEIRA, A.; HELOANI, R.; CASSIOLATO, R. Gestão ambiental nas organizações: desafios para atuação do psicólogo. In. BORGES, L.O.; MOURÃO, L. (Org.). O trabalho e as organizações: atuações a partir da psicologia. Porto Alegre, RS: ARTMED, 2013. p. 181-197

MOSER, G. A psicologia ambiental: competência e contornos de uma disciplina. Comentários a partir das contribuições. Psicologia, USP, v.16, n.1/2, p.279-294, 2005.

https://doi.org/10.1590/S0103-65642005000100030

. Psicologia ambiental. Estudos de Psicologia, v.3, n.1, p.121-130, 1998.

https://doi.org/10.1590/S1413-294X1998000100008

ORLANDI, E. P. Análise do discurso: princípios e procedimentos. 6. ed. Campinas, SP: Pontes, 2005.

PÊCHEUX, M. Semântica do acontecimento: uma crítica afirmação do óbvio. 3. ed. Campinas, SP: UNICAMP, 1997.

POL, E. A gestão ambiental, novo desafio para a psicologia sustentável. Estudos de Psicologia, v.8, n.2, p.235-243, 2003. https://doi.org/10.1590/S1413-294X2003000200005

RICHARDSON, R. J. Pesquisa social: métodos e técnicas. 4. ed. São Paulo: Atlas, 2008.

RODRIGUES, R.R.J. Meio ambiente: ações socioambientais praticadas por empresas. Anais... VI

Congresso Internacional de Psicologia da UEM, Maringá, 19 a 22 de maio de 2015a. 
. Qualidade de vida no trabalho e ações socioambientais sustentáveis. Revista Psicologia e Saúde, Campo Grande, v.2, n.2, p. 177-185, dez. 2015b. ISSN 2177-093X.

. Análise de discurso: fios constitutivos da trama enunciativa. In: HELOANI, R.; SOUZA, R.M. B. de; RODRIGUES, R.R.J. (Org.). Sociedade em transformação: estudo das relações entre trabalho, saúde e subjetividade. Londrina: Eduel, 2015c. v.2, p. 35-58

204f. A identidade discursiva do graduando em psicologia do trabalho: a inexorável presença do outro. (Tese de Doutorado). Estudos da Linguagem. Universidade Estadual de Londrina, Londrina, 2011.

RODRIGUES, R. R. J.; MANSANO, S. R.V. Consumir e descartar: verbos perigosos? In: CAMARGO, H.W.; MANSANO, S.R.V. (Org.). Consumo e modos de vida. Londrina, PR: Syntagma, 2013. p. 8-14

TACHIZAWA, T. Gestão ambiental e responsabilidade social corporativa: estratégias de negócios focadas na realidade brasileira. 4. ed. São Paulo: Atlas, 2007. 